\title{
Struktur komunitas serangga herbivora dan parasitoid pada polong tanaman kacang-kacangan (Fabaceae) di Padang
}

\author{
Community structure of herbivorous insects and parasitoids \\ on pods of legumes (Fabaceae) in Padang
}

\author{
Hasmiandy Hamid* \\ Jurusan Hama dan Penyakit Tumbuhan, Fakultas Pertanian, Universitas Andalas \\ Kampus Unand Limau Manih, Padang 25163
}

(diterima Mei 2012, disetujui Agustus 2012)

\begin{abstract}
ABSTRAK
Kelimpahan dan keanekaragaman serangga herbivora tidak hanya ditentukan oleh tingkat tropik di atasnya, tetapi juga dapat dipengaruhi oleh tingkat tropik di bawahnya. Untuk mempelajari interaksi tritropik antara tumbuhan, serangga herbivora dan parasitoid perlu diketahui struktur komunitas serangga herbivora dan parasitoidnya pada berbagai jenis tumbuhan. Penelitian ini bertujuan untuk mempelajari komunitas serangga herbivora dan parasitoid pada polong berbagai jenis tanaman legum di Padang. Metode yang digunakan dalam penelitian ini adalah metode survei dengan cara mengumpulkan polong tumbuhan legum di berbagai habitat. Serangga yang terdapat di dalam polong dipelihara sampai menjadi dewasa. Individu serangga yang tidak muncul dari polong dikeluarkan dengan membedah polong. Metode ini juga digunakan untuk menaksir jumlah biji, baik biji yang rusak maupun tidak rusak pada masing-masing polong. Hasil penelitian menunjukkan bahwa komposisi serangga herbivora pada polong legum terutama Crotalaria striata didominasi oleh Eucorynus crassicornis, sedangkan komposisi parasitoid didominasi oleh Famili Braconidae. Eucorynus crassicornis memiliki kisaran ekspansi yang lebih luas dibandingkan serangga herbivora lainnya. Serangga tersebut ditemukan pada tiga jenis tanaman legum, yaitu Crotalaria striata, Crotalaria sp., dan Leucaena leucocephala, sedangkan jenis herbivora lainnya hanya menyerang dua jenis legum. Persentase kerusakan tertinggi ditemukan pada Crotalaria striata, yaitu sebesar $74,53 \%$.
\end{abstract}

Kata kunci: serangga herbivora, parasitoid, legum, Eucorynus, Crotalaria

\begin{abstract}
Abundance and diversity of herbivorous insects are not only determined by the trophic level above, but also can be affected by the trophic level below it. This research aims to study the community of herbivorous insects and parasitoids on pods of different types of legume crops in Padang. The method used in this study was a survey method. This method was done by collecting pods of legume plants in various habitats. Insects contained in pods were maintained until adulthood. Individual insects that did not emerge from the pods were removed by dissecting pods. This method was also used to estimate the number of seeds, good seeds were damaged or not damaged in each pod. The results of this study indicated that the composition of herbivorous insects on legumes, especially legume Crotalaria striata was dominated by Eucorynus crassicornis, while the parasitoid composition was dominated by Braconidae. E. crassicornis has a wider range of expansion compared to
\end{abstract}

\footnotetext{
*Penulis korespondensi: Hasmiandy Hamid. Jurusan Hama dan Penyakit Tumbuhan, Fakultas Pertanian, Universitas Andalas, Kampus Unand Limau Manih, Padang 25163

Tel: +6281219543209, Email: hasmiandyhamid@gmail.com
} 
other herbivorous insects. The insects were found on three types of legum C. striata, Crotalaria sp., and Leucaena leucocephala, whereas other types of herbivores attack only two types of legumes. The highest percentage of damage was obtained in Crotalaria striata i.e $74.53 \%$.

Key words: herbivorous insects, parasitoids, legumes, Eucorynus, Crotalaria

\section{PENDAHULUAN}

Sebagian besar legum di Indonesia merupakan tanaman introduksi. Untuk tanaman Crotalaria saja dilaporkan terdapat 32 jenis dan jenis-jenis tersebut masuk ke Indonesia dari berbagai negara asal, misalnya $C$. incana atau orok-orok kebo berasal dari Amerika, dan C. usaramoensis dari Afrika (Sastrapradja \& Afriastini 1984). Tanaman introduksi ini selanjutnya akan berinteraksi dengan serangga-serangga herbivora pada habitat yang baru. Maron \& Vila (2001) mengemukakan bahwa tanaman yang diintroduksi dapat menarik sekelompok herbivora lokal dan herbivora tersebut dapat mengurangi pertumbuhan, produksi biji dan kelangsungan hidup dari tanaman yang diintroduksi. Banyaknya tanaman yang diintroduksi dapat meningkatkan keanekaragaman tanaman pada habitat tersebut. Peningkatan keanekaragaman tanaman secara nyata akan meningkatkan keanekaragaman artropoda. Siemann et al. (1998) mengemukakan bahwa keanekaragaman tanaman juga akan membentuk keanekaragaman herbivora lokal yang selanjutnya juga akan membentuk keanekaragaman parasitoid dan predator pada tingkat tropik yang lebih tinggi.

Penelitian mengenai komunitas serangga herbivora dan parasitoid pada tanaman legum, baik pada tanaman liar maupun tanaman budidaya, masih sangat kurang. Sebagian besar penelitian mengenai serangga herbivora pada legum hanya dilakukan untuk tanaman budi daya saja padahal tanaman liar juga berpotensi sebagai tanaman inang dari serangga herbivora yang juga dapat menyerang tanaman budi daya. Penelitian yang difokuskan pada salah satu bagian tanaman, yaitu polong juga sangat perlu untuk dilakukan karena bagian tanaman ini sering dimanfaatkan oleh manusia dan merupakan organ reproduktif tumbuhan yang berguna dalam penyebarannya. Rasplus (1994) mengemukakan bahwa polong yang dihasilkan oleh tanaman legum dapat digunakan oleh berbagai serangga pemakan biji dan parasitoidnya di daerah tropis. Selain itu, penelitian kekayaan spesies serangga yang diperluas pada lebih dari satu tipe makan mungkin akan berperan terhadap penurunan hasil penelitian yang akan dicapai (Hawkins \& Lawton 1987; Hawkins 1990, 1994).

Penelitian mengenai komunitas serangga pada polong legum telah dilakukan oleh Dolch (2000) dengan membandingkan daerah tropis dan temperate. Di Indonesia sendiri, Mangundojo (1958) telah melakukan penelitian mengenai komunitas serangga pada polong tanaman legum khususnya Crotalaria juncea L. di Jawa, sedangkan Hamid et al. (2008) melakukan penelitian tentang komunitas serangga herbivora dan parasitoidnya pada berbagai jenis tanaman legum di wilayah Sulawesi Tengah. Untuk wilayah Sumatera, khususnya daerah Padang, penelitian komunitas serangga pada polong legum masih sangat kurang. Penelitian pada tanaman legum dilakukan tidak difokuskan pada komunitas serangga herbivora pada bagian tanaman tertentu, tetapi lebih melihat komunitas serangga hama secara umum (My Syahrawati \& Busnia 2009; My Syahrawati et al. 2009). Berdasarkan hal tersebut maka penelitian struktur komunitas serangga hama maupun musuh alaminya (parasitoid) pada tanaman kacang-kacangan sangat penting diketahui karena kompleksitas proses interaksi tingkat tropik yang terjadi di alam sehingga pengetahuan yang diperoleh dapat membantu kita untuk pengelolaan serangga hama yang lebih baik. Penelitian ini bertujuan untuk mempelajari komunitas serangga, utamanya serangga herbivora dan parasitoid pada berbagai jenis polong legum di Padang, penyebaran dan kelimpahan serangga herbivora dan parasitoid pada polong legum, serta kisaran ekspansi serangga herbivora dan parasitoid pada polong legum.

\section{BAHAN DAN METODE}

\section{Waktu dan lokasi penelitian}

Penelitian ini dilaksanakan selama lima bulan yang dimulai pada Juni sampai Oktober 2011. 
Pengambilan sampel polong tanaman legum dilakukan pada beberapa lokasi di kota Padang, Sumatera Barat.

\section{Metode penelitian}

Metode yang digunakan dalam penelitian ini adalah metode survei. Koleksi serangga dilakukan dengan mengumpulkan polong berbagai individu tumbuhan legum, baik tumbuhan tersebut dibudidayakan maupun tidak dibudidayakan. Pengambilan sampel dilakukan pada lokasi tumbuhan tersebut ditemukan, baik pada habitat di tepi jalan, tanah lapang (daerah terbuka) ataupun di lahan pertanian. Pengambilan sampel tersebut dilakukan pada polong yang mulai menua dan polong yang sudah tua. Pengambilan sampel polong muda juga dilakukan jika polong tersebut terserang herbivora.

Semua polong yang dikoleksi selama periode pengamatan dimasukkan ke dalam wadah plastik atau tabung yang tertutup. Satu polong dimasukkan ke dalam satu wadah. Pengamatan dilakukan dengan menghitung total jumlah polong yang dikoleksi, jumlah polong yang rusak, jumlah biji per polong, jumlah dan jenis serangga herbivora serta parasitoid yang muncul dari polong yang dikoleksi. Serangga yang terdapat di dalam polong dipelihara sampai menjadi dewasa. Individu serangga yang tidak muncul dari polong dikeluarkan dengan membedah polong. Metode ini juga digunakan untuk menaksir jumlah biji, baik biji yang rusak maupun tidak rusak pada masingmasing polong.

Pembuatan gambar jaring makanan dari tiga tingkat tropik, polong tumbuhan legum, serangga herbivora dan parasitoid dilakukan dengan menggunakan Software R Statistik versi 2.15.1. for Windows.

\section{Identifikasi serangga herbivora dan parasitoid}

Spesimen serangga yang diperoleh, baik herbivora maupun parasitoid dihitung dan dikelompokkan berdasarkan kesamaan morfospesies. Herbivora dan parasitoid tersebut selanjutnya diidentifikasi sampai ke tingkat famili, sedangkan beberapa spesimen tertentu diidentifikasi sampai ke tingkat genus tergantung kepada ketersediaan kunci identifikasi serangga. Kunci identifikasi yang digunakan berasal dari buku: Australasian Chalcidoidea (Hymenoptera)
(Bouček 1988), dan Hymenoptera of the World: an Identification Guide to Families (Goulet \& Huber 1993). Selain identifikasi menggunakan kunci identifikasi serangga, identifikasi juga dilakukan dengan mencocokkan spesimen serangga dengan spesimen serangga yang didapatkan pada tanaman legum di daerah Toro, gambar dan keterangan dari buku, yaitu The Pests of Crops in Indonesia (Kalshoven 1981) dan Penjelidikan Mengenai Penggerek Polong Crotalaria juncea L. di Jawa (Mangundojo 1958).

\section{HASIL}

Jenis polong legum yang dikoleksi dan persentase serangan serangga herbivora pada legum tersebut pada beberapa lokasi di kota Padang dapat dilihat pada Tabel 1. Secara keseluruhan terdapat 15 jenis tanaman legum yang diambil polongnya untuk sampel. Sebagian besar polong legum yang dikoleksi didominasi oleh Crotalaria striata, Mimosa pudica dan Crotalaria sp. yaitu berturut-turut 746, 390 dan 324 polong. Namun demikian, hanya empat jenis tanaman yang diserang oleh serangga herbivora, yaitu Crotalaria striata, Crotalaria sp., Vigna sinensis dan Leucaena leucocephala, dengan persentase serangan, berturut-turut $74,53 \%, 37,96 \%, 12,96 \%$ dan $6,45 \%$.

Tabel 1. Jenis tanaman legum yang diambil polongnya serta persentase serangan serangga herbivora pada masing-masing legum

\begin{tabular}{|c|c|c|c|}
\hline \multirow[b]{2}{*}{ Jenis tanaman } & \multicolumn{2}{|c|}{ Jumlah polong } & \multirow{2}{*}{$\begin{array}{c}\text { Persentase } \\
\text { serangan } \\
(\%)\end{array}$} \\
\hline & $\begin{array}{c}\text { Tidak } \\
\text { terserang }\end{array}$ & Terserang & \\
\hline Calopogonim sp. & 58 & 0 & 0 \\
\hline Cassia occidentalis & 41 & 0 & 0 \\
\hline Centrosema pubescens & 82 & 0 & 0 \\
\hline Crotalaria sp. & 324 & 123 & 37,96 \\
\hline Crotalaria striata & 746 & 556 & 74,53 \\
\hline Legum sp.1 & 85 & 0 & 0 \\
\hline Legum sp.2 & 156 & 0 & 0 \\
\hline Legum sp.3 & 66 & 0 & 0 \\
\hline Legum sp.4 & 117 & 0 & 0 \\
\hline Legum sp.5 & 73 & 0 & 0 \\
\hline Legum sp.6 & 66 & 0 & 0 \\
\hline Leucaena leucocephala & 124 & 8 & 6,45 \\
\hline Mimosa pudica & 390 & 0 & 0 \\
\hline Pachyrrhizus erosus & 60 & 0 & 0 \\
\hline Vigna sinensis & 54 & 7 & 12,96 \\
\hline
\end{tabular}


Dari hasil penelitian ditemukan bahwa Eucorynus crassicornis dan Blastobasis sp. menyerang tiga jenis tanaman legum, yaitu Crotalaria striata, Crotalaria sp., dan Leucaena leucocephala, sedangkan Etiella zinckenella hanya menyerang dua jenis tanaman legum dan Lampides boeticus serta Maruca textulalis menyerang satu jenis tanaman legum. Serangga parasitoid yang ditemukan menyerang E. crassicornis adalah Eurytoma sp., sedangkan Etiella zinckenella diserang oleh Bracon sp. (Tabel 2; Gambar 1).

Jumlah total seluruh serangga herbivora yang dikumpulkan adalah 1224 individu. E. crassicornis memiliki kelimpahan yang lebih tinggi dibandingkan serangga herbivora lainnya yaitu 895 individu dan diikuti oleh E. zincknella sebanyak 306 individu. Kelimpahan serangga terendah didapatkan pada serangga $L$. boeticus dan M. textulalis sebanyak 7 individu. (Tabel 3; Gambar 1).

Jenis dan kelimpahan parasitoid yang ditemukan menyerang serangga herbivora pada polong legum di kota Padang dapat dilihat pada Tabel 4 dan Gambar 1. Kelimpahan populasi musuh alami didominasi oleh parasitoid dari $E$. zincknella, yaitu famili Braconidae sebesar 177 individu, sedangkan parasitoid E. crassicornis, yaitu famili Eurytomidae sebesar 66 individu.

\section{PEMBAHASAN}

Dari 15 jenis polong tanaman legum yang dikoleksi dari berbagai tempat di Padang, hanya empat jenis tanaman legum yang polongnya

Tabel 2. Berbagai jenis serangga herbivora penggerek polong dan parasitoidnya yang ditemukan pada berbagai jenis legum

\begin{tabular}{|c|c|c|}
\hline Tumbuhan inang & Serangga herbivora & Spesies parasitoid \\
\hline $\begin{array}{l}\text { Crotalaria striata, Crotalaria sp., } \\
\text { Leucaena leucocephala }\end{array}$ & $\begin{array}{l}\text { Eucorynus crassicornis } \\
\text { (Coleoptera: Anthribidae) }\end{array}$ & $\begin{array}{l}\text { Eurytoma sp. } \\
\text { (Hymenoptera: Eurytomidae), }\end{array}$ \\
\hline Crotalaria striata, Crotalaria sp. & $\begin{array}{l}\text { Etiella zinckenella } \\
\text { (Lepidoptera: Pyralidae) }\end{array}$ & $\begin{array}{l}\text { Bracon sp. 1, Bracon sp. } 2 \text { (Hymenoptera: } \\
\text { Braconidae) }\end{array}$ \\
\hline Crotalaria sp. & $\begin{array}{l}\text { Lampides boeticus } \\
\text { (Lepidoptera: Lycaenidae) }\end{array}$ & - \\
\hline $\begin{array}{l}\text { Crotalaria striata, Crotalaria sp., } \\
\text { Leucaena leucocephala }\end{array}$ & $\begin{array}{l}\text { Blastobasis sp. } \\
\text { (Lepidoptera: Blastobasidae) }\end{array}$ & - \\
\hline Vigna unguiculata & $\begin{array}{l}\text { Maruca textulalis } \\
\text { (Lepidoptera: Pyralidae) }\end{array}$ & - \\
\hline
\end{tabular}

Tabel 3. Jenis dan kelimpahan serangga herbivora yang ditemukan menyerang pada polong legum di Padang

\begin{tabular}{lccccrr}
\hline Jenis tanaman & \multicolumn{3}{c}{ Jenis herbivora } & \multicolumn{2}{c}{ Total } \\
\cline { 2 - 6 } & $\begin{array}{l}\text { Etiella } \\
\text { zincknella }\end{array}$ & $\begin{array}{l}\text { Eucorynus } \\
\text { crassicornis }\end{array}$ & $\begin{array}{l}\text { Lampides } \\
\text { boeticus }\end{array}$ & Blastobasis & $\begin{array}{l}\text { Maruca } \\
\text { testulalis }\end{array}$ \\
\hline Crotalaria sp. & 52 & 105 & 7 & 4 & 0 & 169 \\
Crotalaria striata & 254 & 781 & 0 & 4 & 0 & 1039 \\
Leucaena leucocephala & 0 & 9 & 0 & 1 & 0 & 10 \\
Vigna sinensis & 0 & 0 & 0 & 0 & 7 & 7 \\
\hline Total & 306 & 895 & 7 & 9 & 7 & 1224 \\
\hline
\end{tabular}

Tabel 4. Jenis dan kelimpahan parasitoid yang ditemukan menyerang serangga herbivora pada polong legum di Padang

\begin{tabular}{lcrr}
\hline Jenis parasitoid & & Jenis herbivora & Total \\
\cline { 2 - 4 } & Etiella zincknella & Eucorynus crassicornis & \\
\hline Eurytoma sp. (Hymenoptera) & 0 & 66 & 66 \\
Bracon sp.1 (Hymenoptera) & 157 & 0 & 157 \\
Bracon sp.2 (Hymenoptera) & 20 & 0 & 20 \\
\hline Total & 177 & 66 & 243 \\
\hline
\end{tabular}




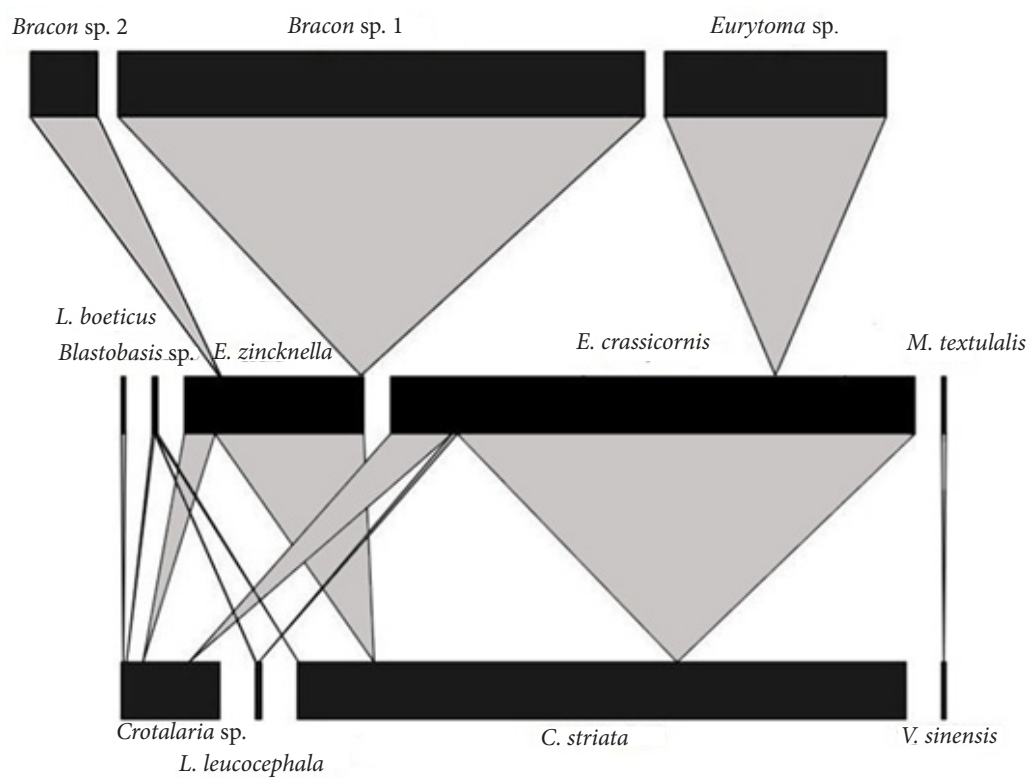

Gambar 1. Jaring makanan pada tiga tingkatan tropik, polong tanaman legum, serangga herbivora dan serangga parasitoid di kota Padang (lebar dari baris tebal hitam menunjukkan kelimpahan individu dari polong tanaman legum, serangga herbivora dan serangga parasitoid, sedangkan ketebalan garis penghubung antara baris menunjukkan frekuensi dari masing-masing interaksi tropik).

dijadikan sebagai inang serangga herbivora, yaitu Crotalaria striata, Crotalaria sp., Vigna sinensis dan Leucaena leucocephala. Sebagian dari tanaman legum yang tidak terserang mungkin disebabkan oleh struktur morfologi polong tanaman legum tersebut yang tidak disukai oleh serangga herbivora. Hal ini dapat dilihat pada polong Mimosa pudica yang memiliki struktur berupa duri yang banyak, begitu pula dengan Legum sp.5 yang memiliki struktur rambut pada permukaan polongnya. Jumlah polong yang dikumpulkan dari tanaman tersebut cukup banyak, tetapi tidak ditemukan serangga herbivora yang menyerang. Sebelumnya Brage et al. (2002) melaporkan bahwa keberadaan trichoma pada spesies Passiflora mengurangi populasi larva Heliconius pada tanaman tersebut. Kennedy (2003) juga melaporkan bahwa trichoma yang terdapat pada tanaman Lycopersicum, berperanan penting terhadap resistensi tanaman tersebut terhadap kutu daun, kutu putih, Helicoverpa zea, Spodoptera exigua, dan Liriomyza trifolii. Carmona, Lajeunesse et al. (2011) selanjutnya mengemukakan bahwa sifat-sifat ketahanan fisik (misalnya keberadaan lateks dan trichoma) juga sering dihubungkan dengan variasi dalam kerentanan herbivora, namun hubungan ini tergantung pada atribut dari herbivora (misalnya feeding guild) dan tanaman (misalnya umur yang 92 panjang). Hal lain yang dapat mempengaruhi serangga herbivora pada tanaman inang adalah kandungan senyawa kimia dan kualitas nutrisi tanaman inang tersebut. Villalba et al. (2002) melaporkan bahwa kemungkinan tumbuhan dimakan oleh herbivora tidak hanya tergantung pada pertahanan kimia saja, tapi juga kualitas dan kuantitas nutrisi tanaman inang dan tanaman sekitarnya. Schuldt et al. (2012) selanjutnya mengemukakan bahwa selain sifat pertahanan dan penampakan tanaman terhadap herbivora, pengukuran distribusi inang secara geografis dalam skala besar merupakan faktor penting yang mempengaruhi pola herbivora lokal di antara spesies tanaman. Keberadaan serangga seperti semut juga dapat mempengaruhi pemanfaatan polong tanaman legum sebagai inang serangga herbivora. Populasi semut yang sangat tinggi pada polong legum dapat mengganggu serangga herbivora yang akan menyerang polong tanaman tersebut. Hal ini dapat ditemukan pada Legum sp. 4.

E. crassicornis merupakan spesies yang umum menyerang pada beberapa polong tanaman legum yang dikumpulkan di kota Padang. Serangga ini merupakan serangga yang kisaran inangnya relatif luas pada polong tanaman legum. Kalshoven (1981) mengemukakan bahwa E. crassicornis dapat menyerang berbagai jenis tumbuhan legum, 
seperti kedelai, Cassia, Indigofera, Vigna, dan Tephrosia vogelii. Selain itu, spesies ini juga dapat menyerang polong tanaman Tephrosia candida dan Sesbania grandiflora walaupun kurang sesuai bagi perkembangannya. Hasil penelitian Hamid et al. (2008) juga menemukan bahwa E. crassicornis dapat menyerang berbagai jenis tumbuhan legum lain, seperti Cassia obtusifolia, Cassia occidentalis, Cassia siamea, Cassia sophera, Centrosema pubescens, Crotalaria striata, Crotalaria usaramoensis, Leucaena leucocephala, Mastersia bakeri, Mucuna pruriens, Sesbania sericea, dan Vigna unguiculata.

Selain memiliki kisaran inang yang lebih luas, E. crassicornis juga lebih dominan dari serangga herbivora lainnya. Hamid et al. (2008) mengemukakan bahwa E. crassicornis merupakan serangga utama yang menyerang pada polong C. striata karena mampu berkembang lebih baik dalam memanfaatkan tumbuhan inangnya dibandingkan serangga lain yang juga menyerang polong C. striata. Selain E. crassicornis, serangga herbivora lain yang kelimpahannya cukup tinggi adalah E. zincknella. Kelimpahan yang tinggi dari E. crassicornis dan E. zincknella menyumbangkan kerusakan yang besar pada polong C. striata, yaitu $74,53 \%$. Hasil yang mirip juga ditemukan Hamid et al. (2008) dari penelitian di Palu dan Toro, yaitu $46,32 \%$ dan $59,52 \%$. Tarigan (2006) mengemukakan bahwa peningkatan populasi serangga herbivora mengakibatkan intensitas serangan pada pertanaman meningkat. Namun demikian, tingkat serangan pada suatu daerah tidak hanya ditentukan oleh populasi serangga herbivoranya, tapi juga dipengaruhi oleh kelimpahan inang, dalam hal ini polong yang tersedia bagi serangga (Hamid et al. 2008).

Tingginya populasi serangga herbivora ini disebabkan kurangnya atau tidak adanya faktor penekan populasinya, yaitu musuh alami. Jumlah populasi musuh alami sebagian besar didominasi oleh parasitoid dari E. zincknella, yaitu dari famili Braconidae sebesar 177 individu, sedangkan parasitoid E. crassicornis sebesar 66 individu. Tooker \& Hanks (2000) mengemukakan bahwa tingginya populasi serangga pemakan tumbuhan diakibatkan tidak adanya faktor yang menekan populasinya. Serangga parasitoid tidak ditemukan pada serangga herbivora lainnya seperti $L$. boeticus, Blastobasis sp. dan M. testulalis. Hal ini disebabkan oleh rendahnya populasi serangga tersebut sehingga kemungkinan ditemukannya serangga parasitoidnya menjadi lebih sedikit (L. boeticus dan Blastobasis sp.). Selain itu, faktor lain, seperti penggunaan pestisida yang berlebihan, dapat mengakibatkan matinya musuh alami terutama parasitoid (M. testulalis). Hasil penelitian Purwantara dan Rauf (2000) menunjukkan bahwa aplikasi insektisida secara nyata menurunkan kelimpahan musuh alami hama (predator dan parasitoid). Secara keseluruhan penurunan populasi musuh alami pada petak yang diaplikasi insektisida berkisar dari $20-78 \%$ relatif terhadap populasi pada petak kontrol. Dari seluruh jenis parasitoid yang ditemukan menyerang serangga herbivora pada polong legum, semuanya tergolong ke dalam ordo Hymenoptera. Quicke (1997) mengemukakan bahwa sekitar $80 \%$ spesies parasitoid termasuk ke dalam Hymenoptera.

\section{KESIMPULAN}

Komunitas serangga herbivora pada tanaman legum didominasi oleh E. crassicornis, sedangkan komunitas parasitoid didominasi oleh Famili Braconidae. E. crassicornis memiliki kisaran ekspansi yang lebih luas dibandingkan serangga herbivora lainnya, karena ditemukan menyerang pada tiga jenis tanaman legum, sedangkan jenis herbivora lainnya hanya menyerang dua jenis polong tanaman legum saja. Kelimpahan yang tinggi dari serangga herbivora pada polong $C$. striata, menyebabkan persentase kerusakan yang tinggi pula pada polong tanaman tersebut, yaitu $74,53 \%$.

\section{UCAPAN TERIMA KASIH}

Ucapan terima kasih disampaikan kepada Tony Sagita, Erni Sugiarti, Lamela Yogna dan Dini Puspita Yanti yang telah membantu dalam penelitian. Ucapan terima kasih juga disampaikan kepada Akhmad Rizali yang telah membantu dalam pembuatan gambar jaring makanan. Penelitian ini merupakan penelitian yang didanai oleh Dana DIPA Universitas Andalas Tahun Anggaran 2011 dengan Surat Perjanjian Pelaksanaan Penelitian Nomor: 06/UN.16/PL/M/ III/2011. 


\section{DAFTAR PUSTAKA}

Bouček Z. 1988. Australasian Chalcidoidea (Hymenoptera): A Biosystematic Revision of Genera of Fourteen Families, with a Reclassification of Species. Wallingford, Oxon: CAB International.

Brage M, Karlsson H, Lundh E, Sandkvist M, Wärnbäck J. 2002. The Role of Trichomes and Nectaries in The Defence Against Insect Herbivores in Passiflora. Ecological methods. Uppsala: SLU (Sveriges lantbruksuniversitet - Swedish University of Agricultural Sciences) Department of Entomology.

Carmona D, Lajeunesse MJ, Johnson MTJ. 2011. Plant traits that predict resistance to herbivores. Functional Ecology 25:358-367. http://dx.doi. org/10.1111/j.1365-2435.2010.01794.x.

Dolch R. 2000. Artenreichtum von Herbivoren-parasitoiden-gesellschaften an Leguminosen: Ein Vergleich Tropischer und Gemäßigter Breiten. Göttingen: Georg-August-Universität-Göttingen.

Goulet H, Huber JT. 1993. Hymenoptera of The World: An Identification Guide to Families. Ottawa, Ontario: Agriculture Canada Publication.

Hamid H, Buchori D, Manuwoto S, Triwidodo H. 2008. Komunitas serangga herbivora dan parasitoid pada polong berbagai jenis Legum di Toro dan sekitarnya (daerah tepian Taman Nasional Lore Lindu). Manggaro 9:6-12.

Hawkins B. 1990. Global patterns of parasitoid assemblage size. Journal of Animal Ecology 59:5772. http://dx.doi.org/10.2307/5158.

Hawkins B. 1994. Pattern and process in hostparasitoid interactions. Cambridge: Cambridge University Press. http://dx.doi.org/10.1017/ CBO9780511721885.

Hawkins B, Lawton J. 1987. Species richness for parasitoids of british phytophagous insects. Nature 326:788-790. http://dx.doi.org/10.1038/ 326788a0.

Kalshoven LGE. 1981. Pests of Crops in Indonesia. Revised by Van der Laan PA. Jakarta: PT. Ichtiar Baru-van Houve. Translation of: Deplagen van de Cultuurgewasen in Indonesie.

Kennedy G. 2003. Tomato, pests, parasitoids, and predators tritrophic interactions involving the genus Lycopersicum. Annual Review of Entomology 48:51-72. http://dx.doi.org/10.1146/annurev. ento.48.091801.112733.

Mangundojo R. 1958. Penjelidikan Mengenai Penggerek Polong Crotalaria juncea L. di Djawa. Djakarta: Fakultas Pertanian, Universitas Indonesia.
Maron J, Vila M. 2001. When do herbivores affect plant invasion? Evidence for the natural enemies and biotic resistance hypotheses. Oikos 95:361-373. http://dx.doi.org/10.1034/j.16000706.2001.950301.x.

My Syahrawati, Arneti, Fitria R. 2009. Hama tanaman bengkuang (Pachyrrhizus erosus urban) di kota Padang. Manggaro 10:31-35.

My Syahrawati, Busnia M. 2009. Serangga hama pada pertanaman kacang panjang (Vigna sinensis (L.) Savi Ex Has) di kota Padang. Manggaro 10:66-70.

Purwantara F, Rauf A. 2000. Pengaruh samping aplikasi insektisida terhadap predator dan parasitoid pada pertanaman kedelai di Cianjur. Buletin Hama dan Penyakit Tumbuhan 12:35-43

Quicke D. 1997. Parasitic Wasp. London: Chapman \& Hall.

Rasplus J. 1994. Parasitoid Communities Associated with West African Seed-feeding Beetles. Parasitoid Community Ecology. Oxford: Oxford University Press.

Sastrapradja S, Afriastini J. 1984. PolongPolongan Perdu. Bogor: Lebaga Ilmu Pengetahuan Indonesia.

Schuldt A, Bruelheide H, Durka W, Eichenberg D, Fischer M, Kröber W, Härdtle W, et al. 2012. Plant traits affecting herbivory on tree recruits in highly diverse subtropical forests. Ecology Leters 15:732-739. http://dx.doi.org/10.1111/j.14610248.2012.01792.x.

Siemann E, Tilman D, Haarstad J, Ritchie M. 1998. Experimental tests of the dependence of Arthropod diversity on plant diversity. The American Naturalist 152:738-750. http://dx.doi. org/10.1086/286204.

Tarigan N. 2006. Jenis-jenis serangga dan intensitas serangannya pada berbagai pola tanam akar wangi. Buletin Teknologi Pertanian 11:1-4.

Tooker J, Hanks L. 2000. Influence of plant community structure on natural enemies of pine needle scale (Homoptera: Diaspididae) in urban landscapes. Environmental Entomology 29:1305-1311. http://dx.doi.org/10.1603/0046225X-29.6.1305

Villalba J, Provenza F, Bryant J. 2002. Consequences of nutrient-toxin interactions for herbivore selectivity: benefits or detriments for plants? Oikos 97:282-292. http://dx.doi.org/10.1034/j.16000706.2002.970214.x 